\title{
The Techno-economic Feasibility of Providing Solar Photovoltaic Backup Power
}

\author{
For load matching at times of loss of grid supply
}

\author{
G. Pillai ${ }^{1}$, J. Hodgson, C. Insaurralde \\ School of Science and Engineering \\ Teesside University \\ Middlesbrough, UK \\ ${ }^{1}$ G.G.Pillai@tees.ac.uk
}

\author{
${ }^{2} \mathrm{M}$. Pinitjitsamut \\ Dept. of Agricultural and Resource \\ Economics, Kasetsart University \\ Bangkok, Thailand \\ ${ }^{2}$ fecomcp@ku.ac.th
}

\author{
${ }^{3}$ S. Deepa \\ Dept. of Electrical Engg. \\ College of Engineering \\ Attingal, India \\ ${ }^{3}$ dipz89feb@gmail.com
}

\begin{abstract}
The availability of energy is a key factor affecting sustainable development. Consumers losing electricity supply due to constraints on electrical power utilities is very common in developing countries. In this paper the technical and economic feasibility of using solar photovoltaics (PV) as a grid independent backup power source which can match the existing consumer load profiles is investigated. A system design methodology that takes into account the seasonal variation in load profiles is developed based on load analysis, PVGIS pre-sizing and PVsyst system performance simulations. The technical and economic performance of the backup system is compared to that for a gridconnected system and a standalone system with scheduled load, all designed for the residential load and weather conditions of a case study location. Impact of shading, a common uncertainty which affects the technical performance of PV systems, on the backup system is also investigated. Results demonstrate the trade-offs in providing solar PV backup power for load matching.
\end{abstract}

Keywords - Sustainable development; photovoltaic; load profile, backup, grid-connected; standalone

\section{INTRODUCTION}

According to the sustainable development commission (http://www.sd-commission.org.uk/) "Sustainable development is development that meets the needs of the present, without compromising the ability of future generations to meet their own needs". Sustainable development in developing countries is closely linked to human activities and therefore energy availability and energy use [1]-[2]. The basic function of every countries' electrical power system is to meet the energy demand of consumers connected to the network [3]. Hence, it has an important role in achieving sustainable development. The power system is a complex infrastructure made of generation, transmission and distribution components. Loss of energy availability affects human activities and therefore sustainable development. There are many scenarios, especially in developing countries, in which the power system is not able to meet the consumer demand such as non-availability of sufficient fuel or resource for generating required electricity, and failure or service (maintenance) of generation, transmission and distribution components that affects delivery of electricity [4]-[5].
The hourly variation in electricity demand is commonly represented by a load profile. Load profiles can be either at the system level representing the aggregate energy consumption of all categories of consumers such as industrial, commercial, residential etc. or it could be at the consumer category level (e.g. residential) [6]. Due to problems in electricity distribution infrastructure and availability of maintenance personal, loss of connection is very common in developing countries. This leads to a condition where energy demand, which can be represented by a certain load profile, exists and remains unmet due to these failures or events. At present, the approach taken to tackle this problem in developing countries is the use of diesel or kerosene backup generators which is environmentally detrimental [7]. For low power requirements battery-inverter systems are also used [8]. These have two main drawbacks: batteries have a short life (typically less than 5 years) especially in high temperature regions and disposal of old batteries harm the environment due to the presence of toxic chemicals in them [9]. In this paper, we investigate the potential for using solar photovoltaics to act as a backup to meet the electricity demand (load profiles) of residential customers so that their activities proceed unhindered and lead to sustainable development.

Initially, a system design methodology that takes into account the seasonal variation in load profiles is developed to size a grid-independent (standalone) backup PV system. The sizing methodology is then compared to that of a gridconnected PV system and a standard load scheduled standalone system. This is followed by an experimental investigation of the impact of an uncertainty common to PV systems in developing countries, the shading of PV modules, on the energy output. The rest of the paper is organised as follows: Section 2 describes the data availability, the methodology for backup system design and its techno-economic analysis; Results are presented and discussed in section 3; and finally conclusions and implications of the study are described in section 4.

\section{MEthodology}

\section{A. Availability of Load Profiles}

For this study, we consider the case of residential PV installations and load profiles. For sizing a PV system in any 
location, the main input is its meteorological data. Since one of the objectives is to achieve load generation matching while considering seasonal variation, seasonal load profiles are required. While the per capita consumption of energy can vary between developed and developing nations, per unitised load profiles have essentially the same features. There are 2 main peaks one in the morning when people leave for work and one in the evening when they return. The match between load and PV generation depends on weather. In the case of standalone PV systems the size of the battery required is influenced by this match [10].

The customary method is recording the energy consumption, at feeder or substation level and averaging this based on the number of customers encompassed to produce the load profiles. Seasonal after diversity maximum demand (ADMD) profiles for the residential category is representative of all house types, family sizes and occupancy patterns. Load profile measurements at customer category levels are highly uncommon among developing nations, unlike in developed nations, owing to the capital requirement. Therefore, load profiling is accomplished by mainly by load research surveys. In many cases the results of these measurements or surveys if undertaken are archived in internal reports that are not easily accessible [11]-[12]. Hence there were few validated load profiles for developing nations, in the public domain, we could access for this study. For this reason the seasonal residential load profiles from UKERC (UK Energy Research Centre) [13] was used and for consistency we considered the meteorological data from a UK location (Middlesbrough) for PV sizing.

\section{B. Backup PV system design}

The backup PV system should be able to cater to the energy demand regardless of the season of the year. This means it should be able to meet both the summer and winter along with the annual energy demand $(3600 \mathrm{kWh}$ for the location considered).

In this study, for the purpose of design, the following considerations were assumed:

-PV design is too meet $100 \%$ demand throughout all seasonal load profiles

-The modules will be roof mounted and there is no limitation on available roof space effecting system sizes.

-There is no budget restriction.

-There will be no shading within the proximity of the chosen location. The effects of shading are considered in section IV.

-The angle of the roof is assumed to be $35^{\circ}$ and it is southfacing.

-As energy storage is required in a stand-alone system, a battery bank will be considered.

-The PV module technology will be monocrystalline silicon

Taking into account the considerations stated the design incorporates the following steps:

1. Identification of maximum daily load

2.Use PVGIS (Photovoltaic Geographic Information System) for pre-sizing the required PV system.

3. Use PVsyst for detailed PV performance simulation to confirm the system size.

\section{Techno-economic analysis}

The results of the design approach for the location considered is presented in the next section. The backup system size and its technical and economic performance is compared against (1) a grid-connected system sized to facilitate the same load-PV-generation matching (assuming no loss of mains) and (2) a standalone system sized to meet the demands of a residential consumer with tight DC load scheduling (doesn't not tolerate seasonal load profile variation). Performance ratio is used as the main metric for technical performance assessment and payback period is used for visualising the economic performance. Performance ratio is defined as:

$$
P R=\frac{\text { Actwal Energy Field }}{\text { Target Energy Yield }}
$$

Whereas, payback period is defined as:

$$
P B T=\frac{\text { Total system cost }}{\text { Annual income }}
$$

Shading from nearby objects is an uncertainty that could influence the PV output and affect the backup PV system from meeting design targets. Therefore, an analysis on the impact of shading, based on laboratory experiments with the monocrystalline module considered in the backup design, is also presented.

\section{RESULTS AND DISCUSSION}

After examining seasonal load profiles throughout the year, the winter load was identified to have the peak value which was $12,290 \mathrm{Wh}$ over the day. Using this value to size the PV system ensures that the system is designed for the worst case load scenario.

\section{A. Load matching}

The initial PVGIS pre-sizing, optimised for peak PV power and battery voltage/capacity, resulted in an estimated backup PV system size of $19.8 \mathrm{~kW}$, with a battery bank of 7000Ah capacity at $72 \mathrm{~V}$. This system was modelled in PVsyst and further iterations of optimisation to reduce the PV array size (while still meeting load profiles) lead to a system size of 10.4 $\mathrm{kW}$, with a battery bank of $2664 \mathrm{Ah}$ at $72 \mathrm{~V}$. Fig. 1 and 2 show the seasonal dynamics of PV generation and load matching. In winter, there is no wastage, PV generation in excess of demand is used for charging the battery bank.

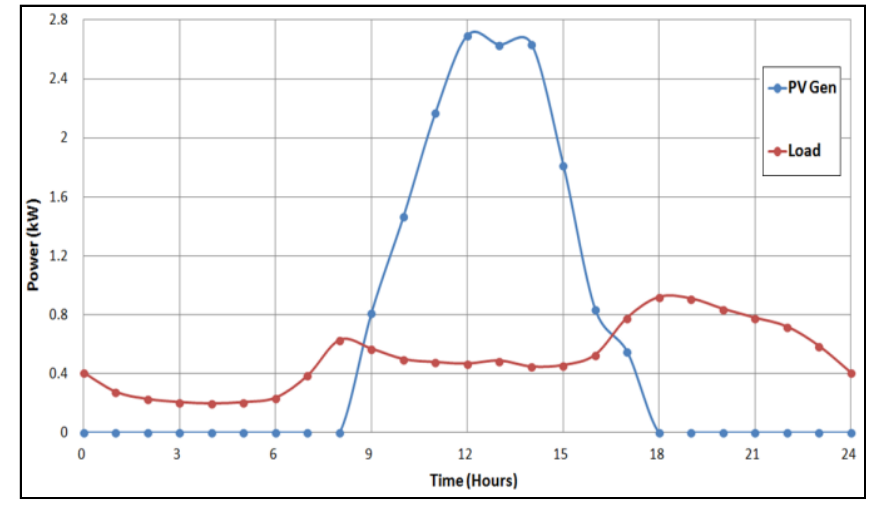

Fig. 1. Winter load profile vs. PV Generation (backup system) 


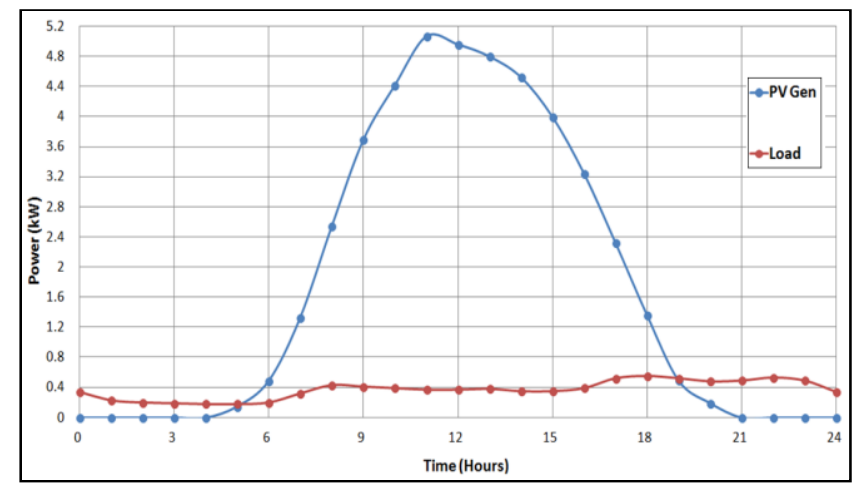

Fig. 2. Summer load profile vs. PV Generation (backup system)

However, in summer, due to low load, there is PV generation in excess of load and battery capacity, which will be wasted. If the target is to achieve load generation matching there is no incentive, especially in cost terms for increasing battery capacity.

A similar design approach: pre-sizing by PVGIS followed by PVsyst modelling and size optimisation was followed for (1) a grid-connected scenario with the same load profiles and (2) a standalone system scenario where the loads are fixed to a schedule. The final systems sizes that resulted are compared to the backup system design in Table I. The PV array size required for both backup and standalone design are considerably greater than that for a grid connected system. This is expected as PV is the only source of energy. Also for the same reason, the area required for both backup and standalone systems is larger, due to the amount of modules needed. This will bring availability of roof top area into question, especially in countries where there is significant shading possibilities due to trees or tall buildings.

TABLE I. COMPARISON OF SYSTEM DESIGNS

\begin{tabular}{|l|c|c|c|}
\hline \multicolumn{1}{|c|}{ Parameter } & Grid connected & Standalone & Backup \\
\hline PV Array $(\mathrm{kW})(\mathrm{STC})$ & 2.4 & 8.8 & 10.4 \\
\hline No. of modules & 12 & 44 & 52 \\
\hline Inverter size (kW) & 2.4 & - & 10.4 \\
\hline Charge controller $(\mathrm{kW})$ & - & 8.6 & 10 \\
\hline Area required $\left(\mathrm{m}^{2}\right)$ & 14.9 & 54.7 & 64.7 \\
\hline Battery Voltage & - & 72 & 72 \\
\hline No of batteries & - & 42 & 54 \\
\hline Stored energy $(\mathrm{kWh})$ & - & 149 & 192 \\
\hline Capacity (Ah) & - & 1184 & 2664 \\
\hline
\end{tabular}

\section{B. System performance}

The backup system size of $10.4 \mathrm{~kW}$ was simulated over an entire year, using the simulation results an annual system performance graph (Fig. 3) was plotted in terms of the energies, expressed as $[\mathrm{kWh} / \mathrm{kWp} /$ day]. There is a large amount of unused energy $(\mathrm{Lu})$ that is wasted due to the battery storage system becoming saturated. The losses within the system (Lc, Ls) account for inverter, array, battery, wiring, regulation losses and all other inefficiencies. The systems yield
(Yf) is defined as the systems useful energy which is consumed by the load. The difference between Yf and $\mathrm{Lu}$ in the summer months shows that the system is oversized w.r.t those parameters, but this size is necessary when the winter months are examined, as there is very little excess energy.

Fig. 4 shows the annual system performance graph for the grid-connected design. It can be seen that there is a minimal amount of losses in the system and in the winter months nearly all the load is consumed. There are greater losses within summer due to the high temperature of the operating system. Using load scheduling reduces the required system size while meeting the annual energy demand of $3600 \mathrm{kWh}$. The annual system performance graph (Fig. 5) for the $8.8 \mathrm{~kW}$ standalone system design shows reductions in unused energy (Lu), system (Ls) and array losses (Lc) compared to the backup system design.

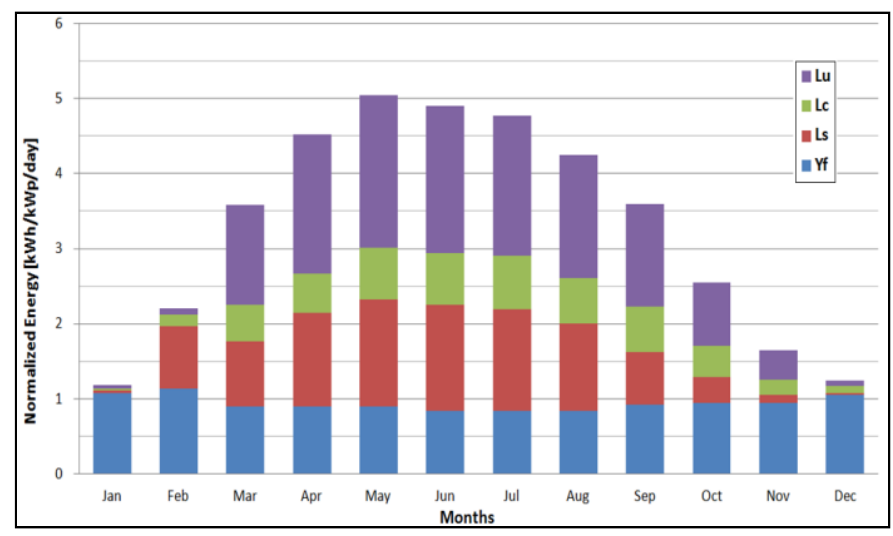

Fig. 3. Annual system performance graph for the backup PV system design

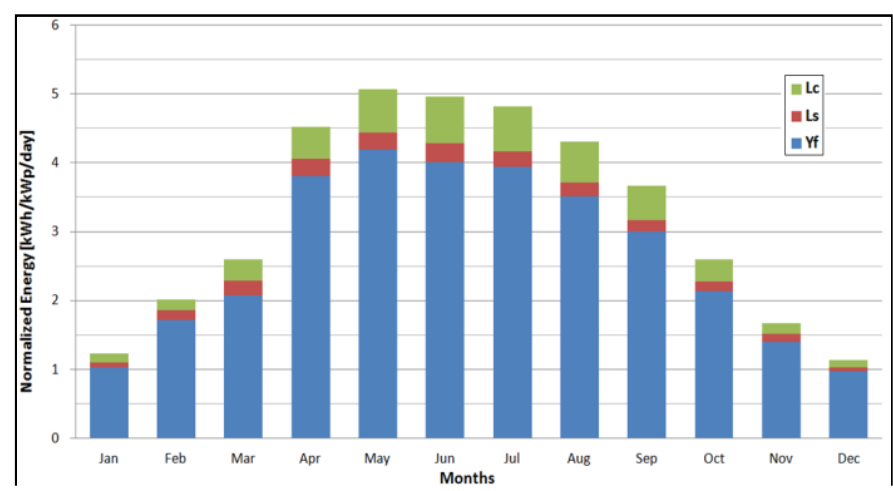

Fig. 4. Annual system performance graph for the grid-connected PV design

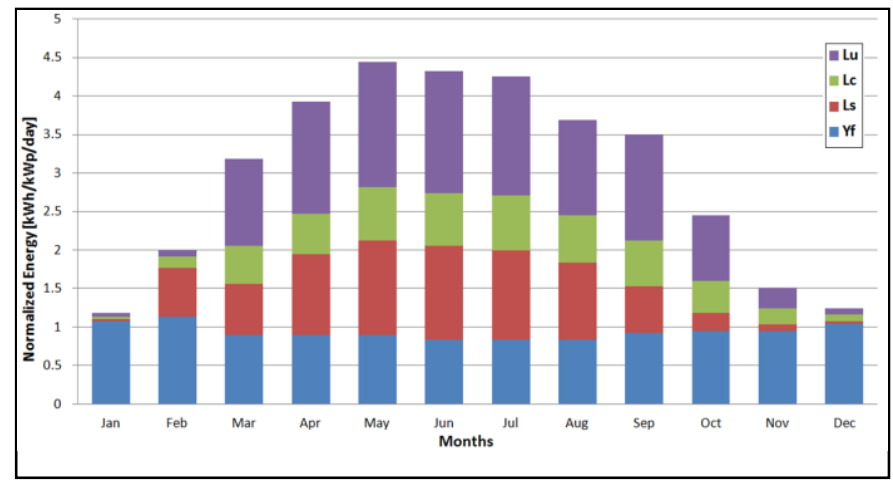

Fig. 5. Annual system performance graph for standalone (load scheduled) PV 
The performance ratio (PR) of a PV system is the relationship between actual energy yield and the target yield. A PR value expresses the losses from the inverter, due to temperature, cable losses, shading losses and losses due to particles on the modules. A system is classed as having a high efficiency if the ratio is above $70 \%$ [14]-[15]. Fig. 6-8 shows the monthly variation in PR respectively for the backup, gridconnected and standalone PV designs. The annual aggregate PR was calculated to be $32.6 \%$ for the backup PV design. The poor PR value is due to the large amounts of losses in the system and the amount of unused energy produced by the array, compared to the useful energy gained. There is only a $7.1 \%$ improvement of PR to $39.7 \%$ through using DC load scheduling. This is far from the PR of $83.9 \%$, which was achieved for the grid-connected design. Both backup and standalone systems achieve such low performances because of the amount of excess energy being produced to ensure the winter seasonal load profiles are met.

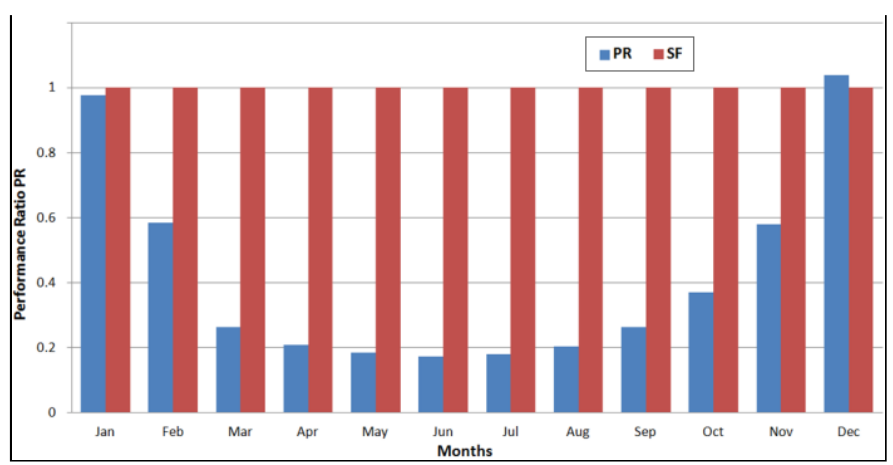

Fig. 6. Monthly variation in performance ratio for the back up PV design

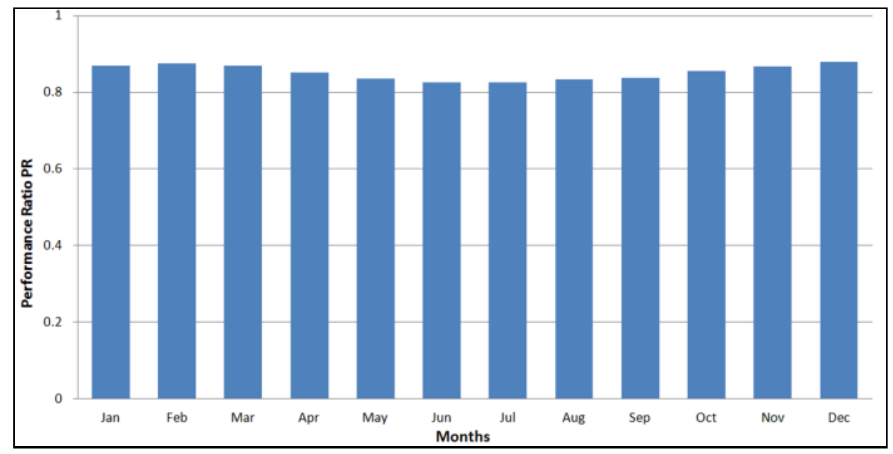

Fig. 7. Monthly variation in performance ratio for grid-connected PV design

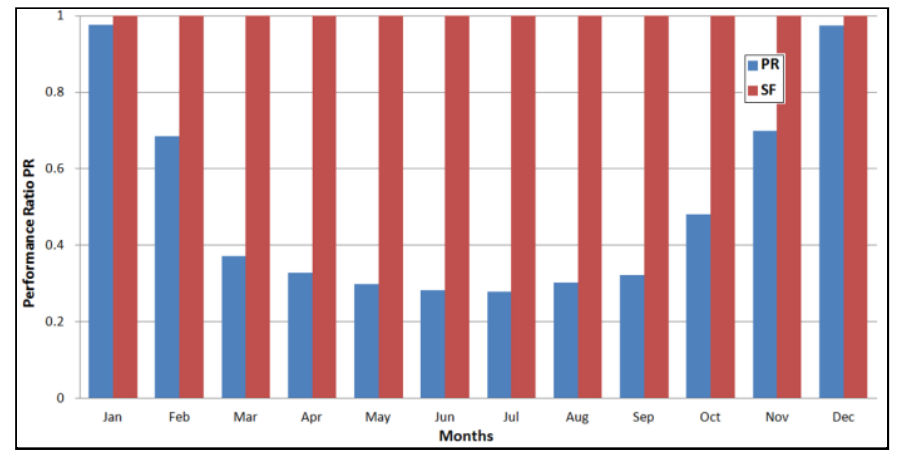

Fig. 8. Monthly variation in performance ratio for the standalone PV design
The Solar Fraction (SF) which is the amount of energy provided by the PV system divided by the total energy required, shown in Fig. 6 and 8 confirms that both grid independent systems match the consumer load profiles.

\section{System Economics}

The total cost for each system design was calculated based on the UK cost of components required for each design. A payback period determines how long it takes for the financial investment to be recouped back from the savings gained from PV generation. It is dependent on several factors, such as energy yield, financial incentives (feed-in tariffs for the case of UK), system size and system costs. Table II shows the total system cost, annual income from feed-in tariffs and the payback period for all three systems designs based on the UK prices and incentives [16].

TABLE II. COMPARISON OF PAYBACK PERIODS

\begin{tabular}{|c|c|c|c|}
\hline System & $\begin{array}{c}\text { System Cost } \\
(\mathfrak{f})\end{array}$ & $\begin{array}{c}\text { Annual } \\
\text { Income (f) }\end{array}$ & $\begin{array}{c}\text { Payback Period } \\
\text { (Years) }\end{array}$ \\
\hline Backup & 30,010 & 812.90 & 36.90 \\
\hline Grid-connected & 4,234 & 446.31 & 9.50 \\
\hline $\begin{array}{c}\text { Standalone (Load } \\
\text { scheduled) }\end{array}$ & 22,424 & 750.9 & 29.9 \\
\hline
\end{tabular}

It can be seen that the cost of the backup system design is seven times greater than that of a grid connected system. Also, the standalone system is five times the cost of the grid connected system. Thus, there is a large cost difference between being connected and not connected to the grid. The cost difference between backup and standalone is approximately $25 \%$. The difference in payback period between the grid connected and the other two systems is three times as long. This is due to the investment needed in the batteries and modules required to produce the necessary amount of energy and the financial incentives. Thus the use of PV systems for backup is costly compared to their normal use in gridconnected mode. However, in a scenarios where loss of grid connection is common, the cost of a backup system is comparable and could be used instead of standalone systems as the quality of life is not affected by having to use energy according to a predetermined schedule.

\section{Effects of shading}

For any backup energy system, there should be a guaranteed output. However for PV systems, there are factors which are commonly beyond the control of the user/installer such as the weather, and the possibility of shading from nearby objects which affects the energy output. Experiments were carried out with the monocrystalline PV modules considered for the system design under controlled conditions at the electrical power laboratory in Teesside University. When there is a variation in irradiance either due to weather (uniform over module area) or through shading (not uniform), the PV inverter's search algorithm tries to find the new maximum power point (MPP). The output power from the PV array, the voltage and current depends on the MPP. If the MPP is located outside the inverter's MPP voltage range then the algorithm 
will keep searching, but will not be able to find the MPP and the output power falls to a very low value.

Fig. 9 shows the power-voltage (P-V) (magenta) and current-voltage (I-V)(blue) curves for the array considered at $100 \%$ irradiance $(1000 \mathrm{~W} /$ sq.m. $)$ The MPP as tracked by the inverters algorithm is denoted as a circle on the P-V curve. Fig. 10 shows the impact of increasing shading to $100 \%$. Even though there is a possible MPP, the inverter cannot track as it is outside its voltage range.

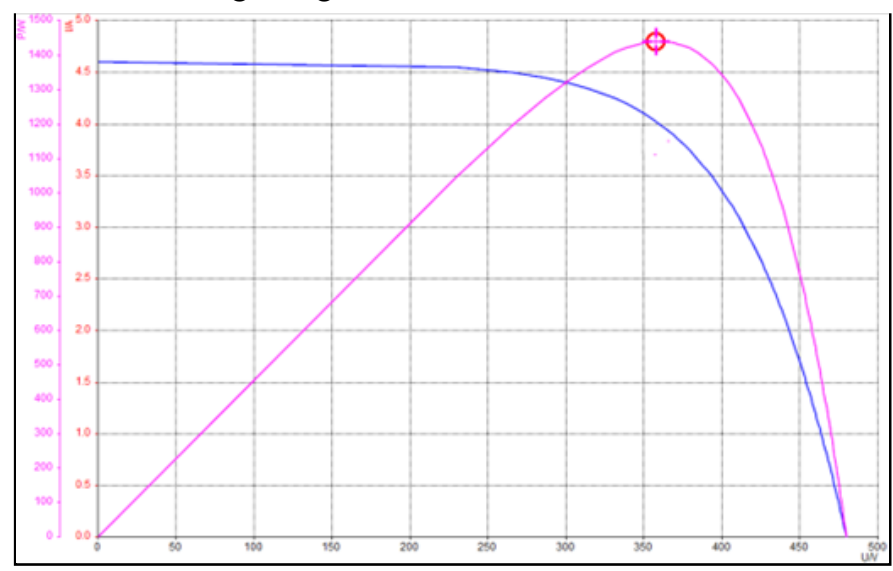

Fig. 9. MPP tracking under $100 \%$ irradiance and no shading

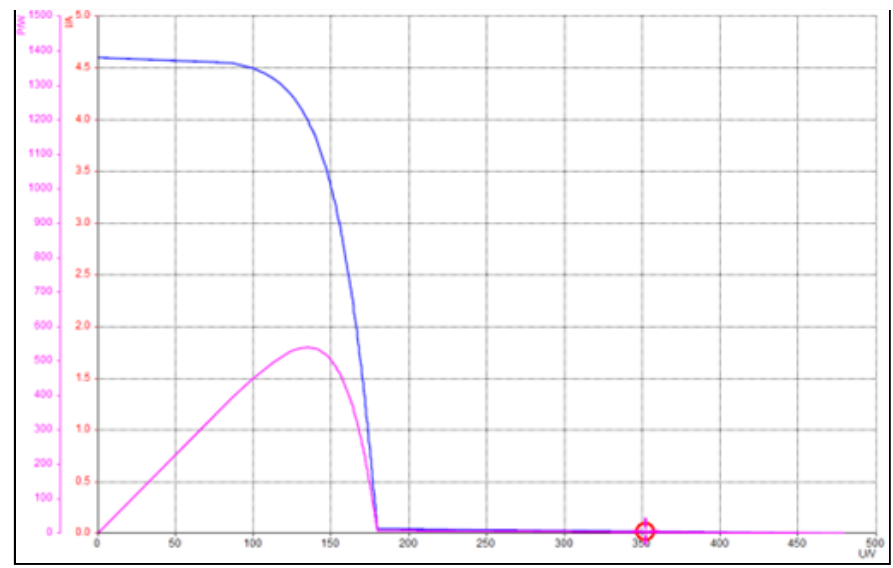

Fig. 10. MPP tracking under $100 \%$ irradiance and $100 \%$ shading

Table III shows the impact of increasing percentages of shading on the array output.

TABLE III. MPP WITH FURTHER SHADING

\begin{tabular}{|c|c|c|c|}
\hline Shading (\%) & $\begin{array}{c}\text { Array output } \\
\text { power (W) }\end{array}$ & Voltage (V) & Current (A) \\
\hline 0 & 1440 & 360 & 4.03 \\
\hline 20 & 1215 & 369 & 3.29 \\
\hline 50 & 791 & 376 & 2.10 \\
\hline 80 & 339 & 385 & 0.88 \\
\hline 100 & 9 & 352 & 0.02 \\
\hline
\end{tabular}

It can be seen that the current and consequently the energy output drastically reduces with shading. Because it is an engineering uncertainty, the possible frequency of shading events could be incorporated into the design software itself if the developers follow Dependable Software Systems (DSS) approaches [17]. This can then provide a guaranteed range of energy output for PV system designs which is not possible presently and is a design risk that particularly affects backup PV system design.

\section{CONCLUSIONS}

The availability of energy is a key factor affecting sustainable development. Consumers losing electricity supply due to constraints on electrical power utilities is very common in developing countries. The technical and economic feasibility of using solar photovoltaics (PV) as a grid independent backup power source which can match the existing consumer load profiles was investigated in this paper. Firstly, a system design methodology that takes into account the seasonal variation in load profiles is developed based on analysis of seasonal load profiles, PVGIS pre-sizing and PVsyst system performance simulations leading to size optimisation. The technical and economic performance of the backup PV system designed is compared to that for a grid-connected design and a standalone system designed for scheduled load. The non-availability of load profiles lead to the comparison of the performance of these systems design under the residential load and weather conditions of a case study location in UK. Impact of shading, a common uncertainty which affects the technical performance of PV systems, on the backup system was also investigated. Results demonstrated that for achieving load matching while the cost of a backup PV system is very high in comparison to a grid-connected, it is only about $25 \%$ more costly than a standalone system. The standalone system was considered with DC loads fixed to a particular schedule. If we consider AC load the cost compared to a backup PV system will be less than $25 \%$ due to the need for a DC to AC inverter. In performance terms, there was no guarantee of output due to the possibility of shading. If the developers of software like PVsyst incorporate DSS approaches, at least for locational performance simulation in developing countries, a guaranteed PV energy output range can be estimated.

\section{REFERENCES}

[1] M. Pinitjitsamut, "Energy Sustainability in Thailand", OIDA International Journal of Sustainable Development, vol. 4, no. 7, p. 83, 2012.

[2] A. Kemmler and D. Spreng, "Energy indicators for tracking sustainability in developing countries", Energy Policy, vol. 35, no. 4, pp. 2466-2480, 2007.

[3] A. Bayod-Rújula, "Future development of the electricity systems with distributed generation", Energy, vol. 34, no. 3, pp. 377-383, 2009.

[4] A. Sarkar and J. Singh, "Financing energy efficiency in developing countries-lessons learned and remaining challenges", Energy Policy, vol. 38, no. 10, pp. 5560-5571, 2010.

[5] P. Mozumder and A. Marathe, "Causality relationship between electricity consumption and GDP in Bangladesh", Energy Policy, vol. 35, no. 1, pp. 395-402, 2007.

[6] L. Chuan and A. Ukil, "Modeling and Validation of Electrical Load Profiling in Residential Buildings in Singapore", IEEE Trans. Power Syst., vol. 30, no. 5, pp. 2800-2809, 2015.

[7] M. Kanagawa and T. Nakata, "Assessment of access to electricity and the socio-economic impacts in rural areas of developing countries", Energy Policy, vol. 36, no. 6, pp. 2016-2029, 2008. 
[8] "Buying home battery inverter systems", 2016. [Online]. Available: http://www.electromaticsolar.com/tips-to-buy-inverter-and-battery-forhome/. [Accessed: 14- Jul- 2016].

[9] K. Cavanagh, S. Behrens, C. Price, O. Lim, N. Haigh, A. Fleming, E Oliver, A. Mankad and A. Bhatt, "Energy storage safety: Responsible installation, use and disposal of domestic and small commercial battery systems", Clean Energy Council, Australia, 2015.

[10] P. Nikhil and D. Subhakar, "Approaches for Developing a Regression Model for Sizing a Stand-Alone Photovoltaic System", IEEE Journal of Photovoltaics, vol. 5, no. 1, pp. 250-257, 2015.

[11] D. Sailor, "Relating residential and commercial sector electricity loads to climate-evaluating state level sensitivities and vulnerabilities", Energy, vol. 26, no. 7, pp. 645-657, 2001.

[12] G. Pillai, G. Putrus and N. Pearsall, "Generation of synthetic benchmark electrical load profiles using publicly available load and weather data", International Journal of Electrical Power \& Energy Systems, vol. 61, pp. 1-10, 2014.

[13] "UKERC Energy Data Centre - Data Archive", Ukedc.rl.ac.uk, 2016. [Online]. Available: http://ukedc.rl.ac.uk/data.html. [Accessed: 13- Jul2016].
[14] "Performance Ratio - SolarServer", Solarserver.com, 2016. [Online]. Available:

http://www.solarserver.com/knowledge/lexicon/p/performanceratio.html. [Accessed: 13- Jul- 2016].

[15] "Annual Solar Irradiance", Greenrhinoenergy.com, 2016. [Online]. Available:

http://www.greenrhinoenergy.com/solar/radiation/empiricalevidence.php . [Accessed: 13- Jul- 2016].

[16] "DECC Announcements - GOV.UK", Gov.uk, 2016. [Online]. Available:

https:/www.gov.uk/government/announcements?keywords=fit\&announ cement_filter_option=all\&topics $\% 5 \mathrm{~B} \% 5 \mathrm{D}=$ all\&departments $\% 5 \mathrm{~B} \% 5 \mathrm{D}=$ department-of-energy-climate-

change\&world locations $\% 5 \mathrm{~B} \% 5 \mathrm{D}=$ all $\&$ from date $=\&$ to_date $=$. [Accessed: 13- Jul- 2016].

[17] C. C. Insaurralde, "Model-merged development for analysis and design of dependable software systems", in Systems Conference (SysCon), 2013 IEEE International, Orlando, FL, 2013, pp. 164-169. 